\title{
Santiago Ramón y Cajal a Barcelona
}

\author{
Elvira Rocha Barral \\ Professora jubilada de Secundària \\ elvirarocha@arrakis.es
}

L'estada de Santiago Ramón y Cajal a Barcelona va coincidir amb un fructífer període de la seva vida durant el qual, malgrat totes les dificultats, va aconseguir el reconeixement de la comunitat científica internacional.

Paraules clau: història de la ciència, neurologia, microscòpia, tincions, neurona, Ramón y Cajal, Barcelona

\section{Les recerques sobre el teixit nerviós}

El desenvolupament de la citologia i de la histologia progressà notablement a partir de la formulació de la teoria cel.lular que M.J. Schleiden (18041881) i T. Schwann (1840-1882) aportaren a la recerca microscòpica de la constitució íntima dels éssers vius (1838 i 1839). Significaren innovacions en tècniques microscòpiques així com progressos en mètodes de tinció i preparació del teixits vegetals i animals, contribuint de manera definitiva a la construcció del coneixement d'aquestes modernes especialitats de la biologia.

Però dificultats materials (de preparació i tinció), així com prejudicis extracientífics, van dificultar l'avenç del coneixement microscòpic del teixit nerviós, així com la comprensió -i, per tant, la possibilitat d'establir la dinàmica- del sistema que constituïa. Les primeres tincions basades en carmí i hemotoxilina van anar sent substituïdes per aplicacions de nitrat de plata sobre peces endurides prèviament amb dicromat potàssic. Més endavant aquestes peces es pogueren observar mitjançant noves tècniques de fixació, inclusió i posterior seccionament utilitzant microscopis amb lents que ja corregien les aberracions òptiques.

Tot i així, i ja definits i identificats l'axó i les prolongacions protoplasmàtiques (dendrites) de la cèl-lula nerviosa, es tenia la convicció que, en conjunt, el sistema nerviós constava d'una xarxa difusa anastomosada (connexió de fibres): o bé mantenia fusionades entre si el conjunt de les seves dendri- tes (J.v. Gerlach, 1820-1896) o la xarxa difusa estava formada per axons (C. Golgi, 1843-1926). La teoria establerta com a "reticularisme" corresponia a aquesta concepció materialitzada segons la qual el sistema nerviós havia de constituir, per la seva pròpia naturalesa i comportament, una xarxa difusa.

\section{Les recerques de Ramón y Cajal a Barcelona}

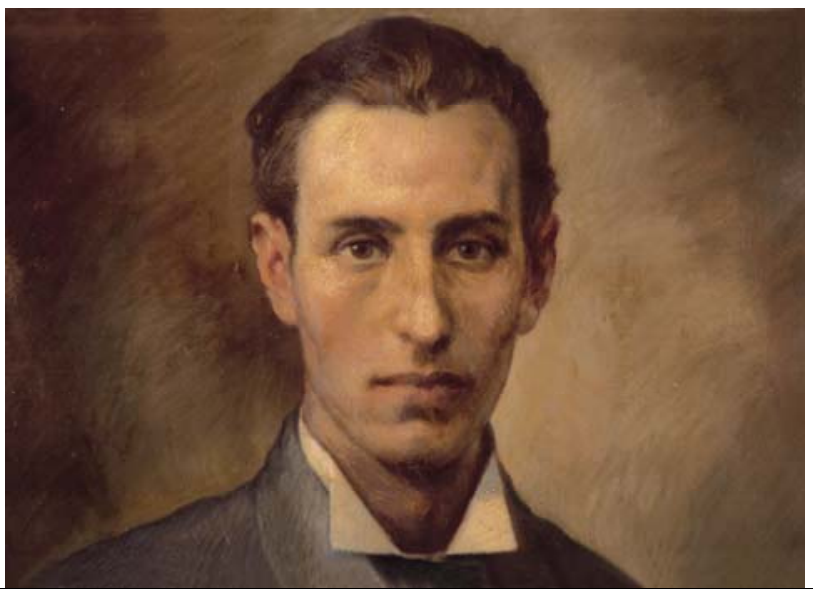

Figura 1. Santiago Ramón y Cajal (1852-1834)

Santiago Ramón y Cajal (1852-1934) arriba a Barcelona a finals de l'any 1887 procedent de la Facultat de Medicina de la Universitat de València (fig. 1). 


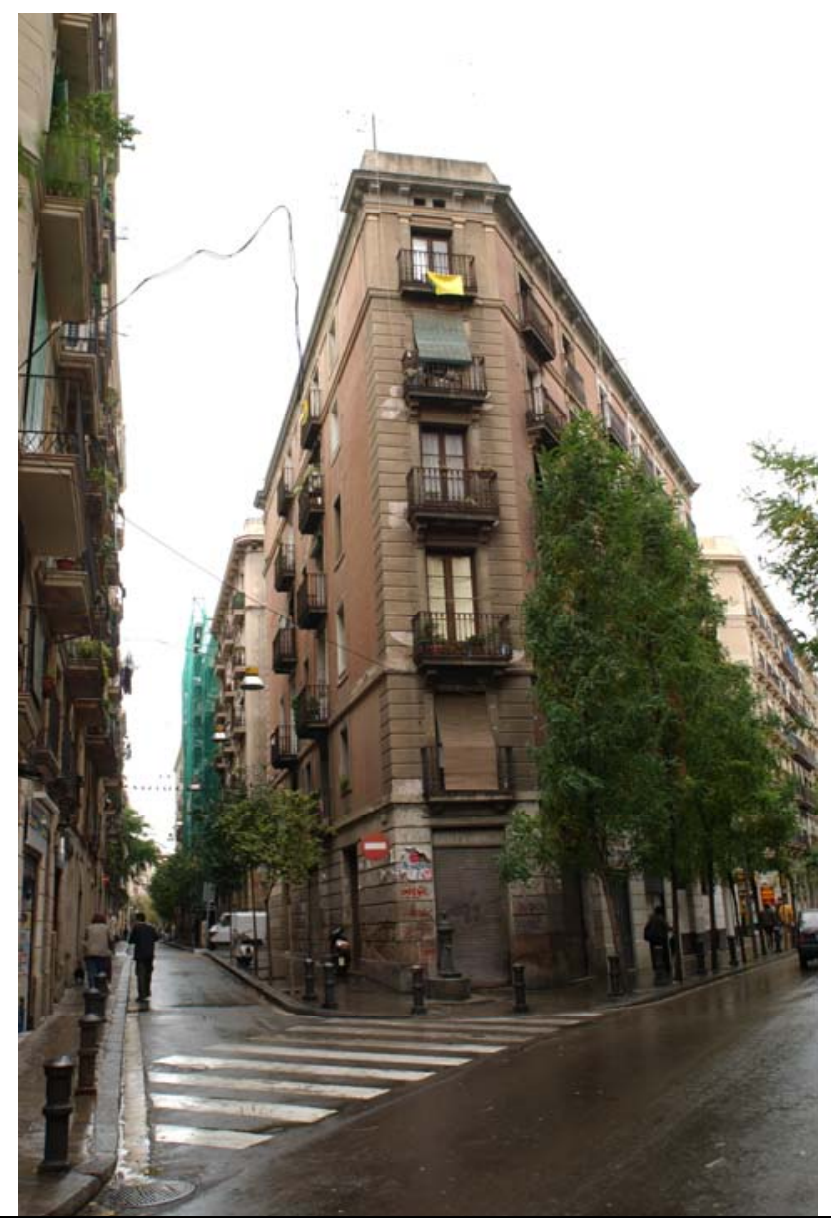

Figura 2. Edifici Miquel Faralt, carrer de la Lluna, 1. Primer habitatge de la família Ramón-Fañanás a Barcelona.

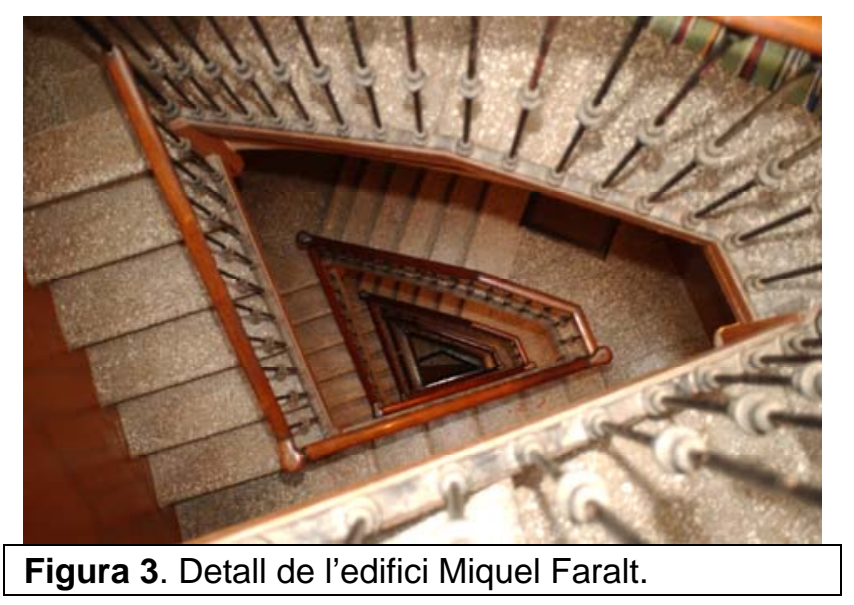

A València havia exercit com a titular de la càtedra d'Anatomia i ja havia assajat la tècnica de Golgi per observar el teixit nerviós: una tècnica basada en sals de plata i coneguda com a reacció negra. Posseïa un microscopi Zeiss, dotat de les darreres innovacions òptiques incorporades per aquesta empresa alemanya. A la Facultat de Barcelona s'estrena com a titular de la càtedra d'Histologia.

Arriba amb la seva esposa Silveria i cinc fills: Fe, Santiago, Paula, Jorge i Enriqueta. S'instal.la en el número 1 del carrer de la Lluna, 2n, 2a (figs. 2 i 3). L'edifici de la seva Facultat no li queda lluny: és el que avui dia acull la Reial Acadèmia de Medicina.

Cajal sap, el 1888, que una part important dels especialistes en l'estudi microscòpic del sistema nerviós manifesten els seus dubtes a propòsit del reticularisme: R. A. v. Kölliker (1817-1905) ja ho havia fet constar en la seva obra de 1868; W. His (1831-1904) i A.H. Forel (1848-1931) així ho havien expressat, encara que més tímidament, feia amb prou feines un any. Sens dubte, la concepció moderna, no reticularista, del sistema nerviós, estava a punt d'enunciar-se. Els científics especialistes en sistema nerviós -gran part d'ells titulats de centres de recerca de països centreeuropeus- manifestaven la receptivitat imprescindible per als grans canvis teòrics. Falta molt poc perquè la tècnica permeti demostrar la materialitat de la nova concepció que ja s'entreveu (i que es dirà neuronisme).

Amb diverses modificacions del mètode de Golgi (doble i triple impregnació), Cajal aconsegueix la visualització indiscutible que destronarà les antigues teories reticularistes.

L'octubre de 1889 viatja amb els seus resultats, és a dir, amb les seves preparacions microscòpiques, a Berlín. Allà s'hi han de celebrar les jornades del Congrés de la Societat d'Anatomia Alemanya, a la qual pertany. Kölliker, juntament amb quasi tots els històlegs que hi assistien, acullen amb entusiasme les idees de Cajal. Els documents continguts en els arxius de la Universitat de BarceIona acrediten detalladament aquest esdeveniment: un mes sense sou, cap remuneració per al viatge en un vagó de tercera ni cap comentari a la seva tornada.

L'estudi detallat de cadascuna de les seves publicacions al llarg d'aquesta època barcelonina, ordenant-ne els continguts i les seves concordances atenent a les dates de producció de cada treball, comparades amb dates, número i revista de les seves publicacions, permet desvelar els nombrosos entrebancs que Cajal va haver de suportar: imposició d'un torn d'espera en alguna de les revistes de fins a tres mesos, fragmentació obligada dels treballs en altres, impossibilitat d'inclusió de totes les imatges que el tema requeria o de tota la bibliografia que l'autor considerava imprescindible, així com altres dificultats que, òbviament, devien enervar la comprensible impaciència de Cajal. 


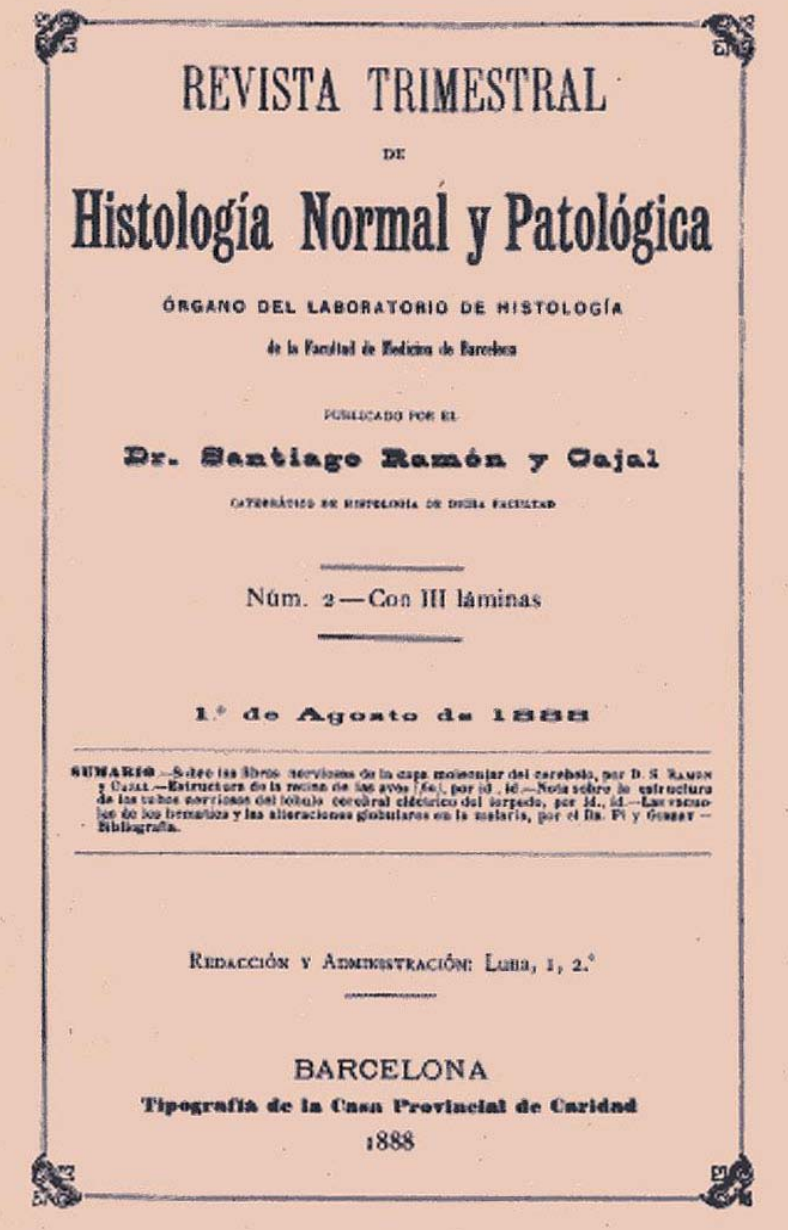

Figura 4. Portada de la "Revista Trimestral de Histología normal y patológica".

Ell coneixia millor que ningú la vertiginosa cursa en què els investigadors internacionals estaven immersos amb l'afany d'arribar el més aviat possible a una meta que ja es pressentia imminent.

Tot plegat havia forçat Cajal a publicar, pagantlo de la seva butxaca, el primer de maig de 1888 , cinc mesos després d'haver-se incorporat a la seva nova càtedra, el número 1 de la "Revista Trimestral de Histología Normal y Patológica" (fig. 4), els exemplars de la qual repartiria la família des del seu propi domicili. Als quinze dies apareix el seu primer treball a la "Gaceta Médica de Cataluña" (fig. 5).

Més endavant, i en millors condicions editorials, escriu a la "Gaceta Sanitaria de Barcelona" (fig.6). Entremig publica altres articles en revistes estrangeres de gran difusió i qualitat, al mateix temps que, com a investigacions de la Facultat, apareixen "pequeñas comunicaciones anatómicas...", "pequeñas contribuciones...", "Trabajos de Laboratorio".

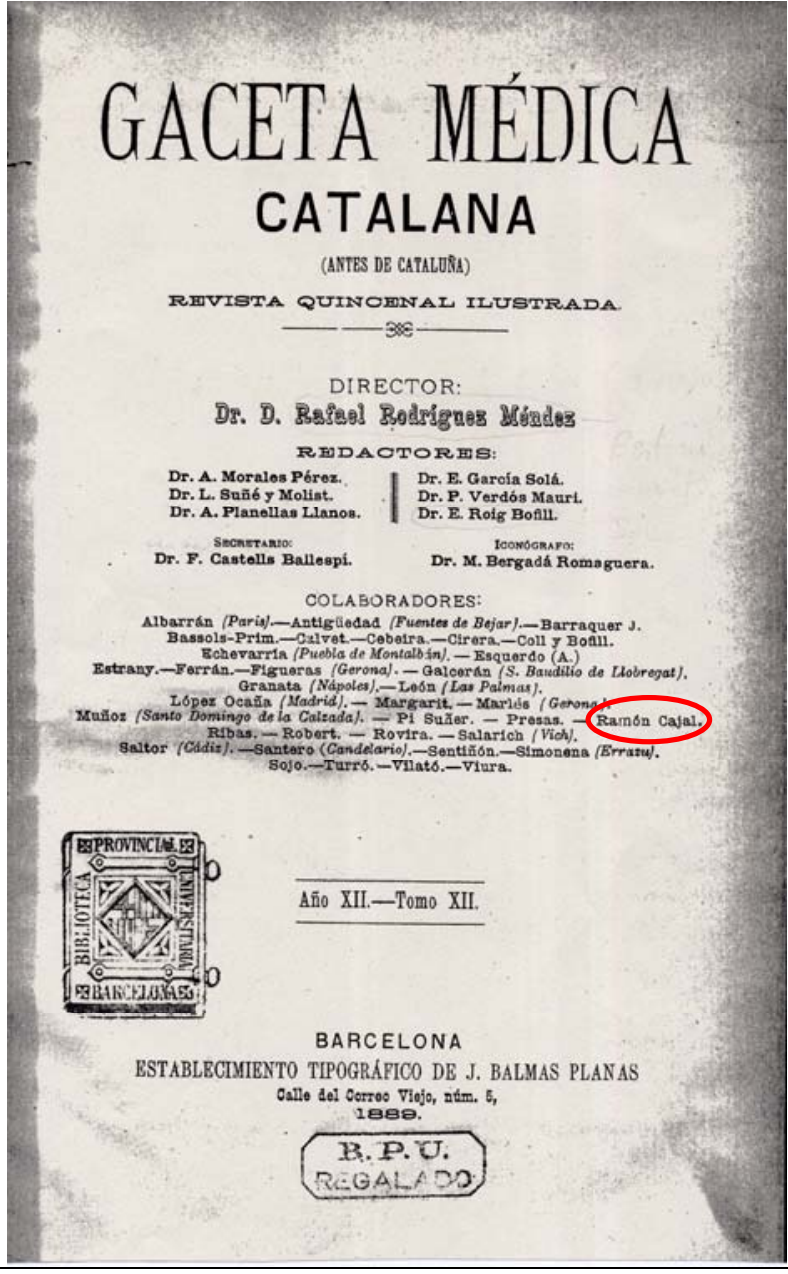

Figura 5. Portada de la "Gaceta Médica de Cataluña", on Ramón y Cajal consta entre els col/laboradors.

Finalment, és en la "Revista de Ciencias Médicas de Barcelona" on quedaren recollides, entre altres novetats, les seves darreres conferències impartides a I'"Academia y Laboratorio de Ciencias Médicas de Cataluña" (fig. 7). El contingut d'aquestes tres sessions -el text de les quals fou traduït al francès i a l'alemany- constitueix el missatge contundent que va situar Ramón y Cajal entre els primers especialistes mundials de la investigació del segle XIX.

En aquests anys, treballant sobre estructures com el cerebel, la retina, la medul.la, el cervell i altres, utilitzant embrions de diversos vertebrats petits, Cajal contribueix a desautoritzar l'existència de la xarxa difusa que defensaven els reticularistes. Demostra amb les seves preparacions i mitjançant expressius i irrevocables dibuixos interpretatius que entre les terminacions nervioses existeix contacte o contigüitat, però no anastomosi.

El 1891 envia al Primer Congreso Mèdico-Farmacéutico Regional celebrat a València una comu- 
nicació en la que formula la llei de polarització dinàmica de la neurona, segons la qual la transmissió de l'impuls nerviós es produeix sempre des d'una de les ramificacions protoplasmàtiques i el cos cel.lular cap a l'axó, de forma que es pot considerar que tota neurona posseeix un aparell receptor (dendrites i soma) i un aparell emissor (axó) amb terminacions que constitueixen un aparell distribuïdor (arboritzacions terminals). Durant aquest període observà i descrigué els cons de creixement de la neurona, confirmant així la teoria neurogenètica de W. His.
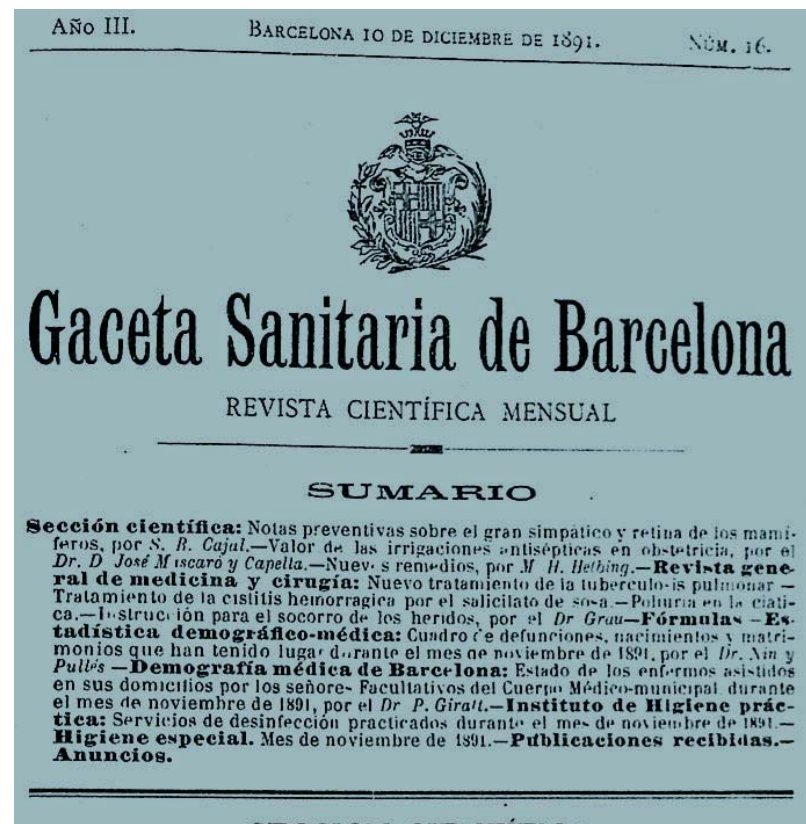

SECCION CIENTÍFICA

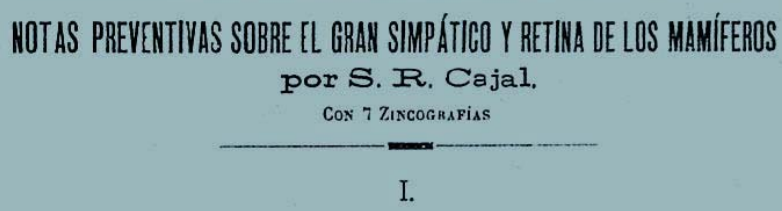

LA RETINA DE LOS MaMiferos

Deseando confirmar en los mamíeros algunos hillazgos de la retina de los batracios y reptiles, y completar en lo que de mí dependiese, el notable trabajo de Tartuferi, primer autor que aplicó a la retina el valiosísimo método de la coloración negra de Golgi, hémonos entregado recientemente $a$ investigaciones en el conejo, gato, buey, carnero y perro, de las cuales vamos brevemente i esponer lo principal, reservando ciertos detalles, $y$ algunos desenvolvimientos fisiológicos para una monografia de conjunto que en breve publicaremos.

Figura 6. Portada de la "Gaceta Sanitaria de Barcelona".

Durant la seva estada a València, Ramón y Cajal havia publicat un "Manual de Histología normal y de técnica micrográfica”. A Barcelona la seva tasca docent quedà enriquida amb la publicació d'un "Manual de anatomia patológica general", seguida d'un resum de microscòpia aplicada a la histologia i bacteriologia patològiques.

\section{Els treballs posteriors}

Però la seva gran obra apareixeria, ja a Madrid, primer per fascicles i després en dos toms (el segon, de dos volums) entre 1899 i 1905: "Textura del sistema nervioso del hombre y de los vertebrados".
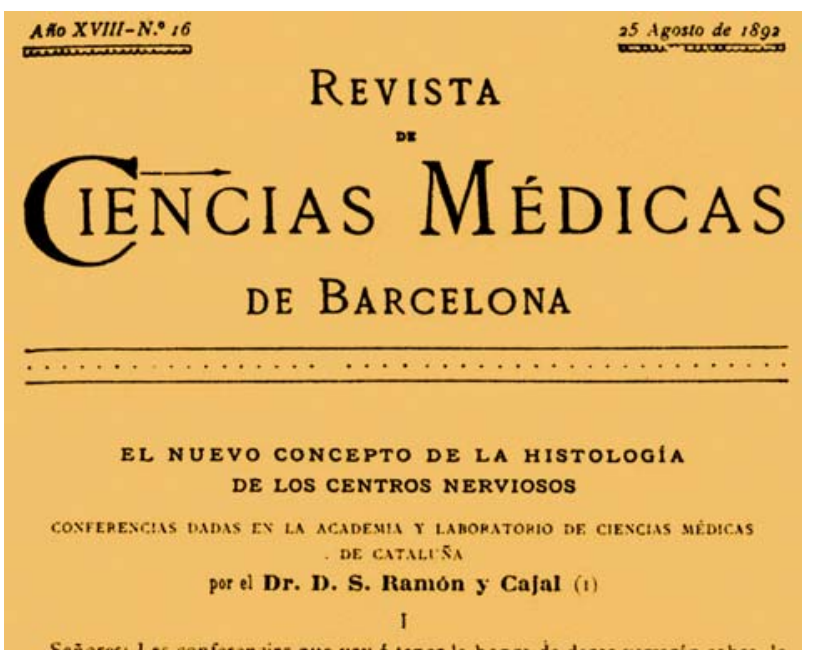

Señores: L.as conferencias que vơ á tener la honra de daros versarán sobre la nueva histologia de los centros nerviosos, materia que ya conocéis, sobre todo. después de las brillantes lecciones que hace dos años expuso aqui sobre el asunto uno de vuestros miembros más inteligentes y estudiosos, el Dr. Durán y Ventosa. Pero de entonces acá, si no se han hecho grandes progresos, se han consolidado doctrinas antes inseguras, $y$ han tomado definitivamente carta de naturaleza en la ciencia ideas que en la época en que tuve el honor de publicarlas, parecieron á los sabios un tanto arriespadas. Juzgo, pues, que no será inútil presentar la iase actuai de la cuestiỏn, contrayéndonos á los datos más esenciales yá los resultados que pueden darse como completamente probados. Por otra parte, entiendo que una cxposición sintética del asunto es tanto más necesaria cuanto que no existe actualmente ningủn tibro en que se resuman y valoren todas las recientes y ya -

(1) Las incorrecciones que resultaron en las notas taquigráficas tomadas durante las conferencia han decidido al autor, en obsequio ál la REvista, á escribirlas de nuevo y, conservando la forma primitiva, variar algo ei orden que, por la escasez del tiempo. no habia sido el mas a a lector que carece de los medios de demostración hue tuso el público oyente. Asi. pracias a la bondad del Dr. Cajal, nunca por nosotros bastante asradecida. podemos publicar este precioso trabajo que constituye el primer resumen en espaniol de la totalidad de los estudios modernos acerea de la histologia de los centros nerviosos, que prestará un servicio inapreciable á los que deseen enterarse rápidamente de la substancia de tor descitrimientos que en el extranjero han sido ya resumidos : ulparizados por Kolliket, van Geluuchten y Waideyer, y en los cuales tan ploriosamente

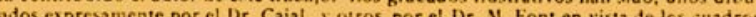
que expuso ci autor en sus conferencias, - (Nota de la Rivista.)

Figura 7. Portada de la "Revista de Ciencias Médicas de Barcelona" on es recullen les conferències de Barcelona que, traduïdes, van proporcionar a Cajal una enorme fama per tot Europa el 1892, tot just quan deixava la càtedra de la ciutat.

També a Madrid el 1896 apareix el primer número de la Revista Trimestral Micrográfica (que no té res a veure amb la col-lecció de títol semblant que va publicar modestament a Barcelona i que molts autors confonen) que a partir del número 5 
continuaria com a Trabajos del Laboratorio de Investigaciones Biológicas de la Universidad de Madrid. Aquesta col-lecció, sens dubte emblemàtica en el conjunt de la seva obra, va aparèixer periòdicament, amb algunes sèries en versió francesa, més enllà de l'any 1934, any del traspàs de Cajal.

Investigador d'una fecunditat indiscutible va crear, modificar i assajar centenars de tècniques microgràfiques que va reunir en la seva obra de 1933: Elementos de técnica micrográfica del sistema nervioso (fig. 8).

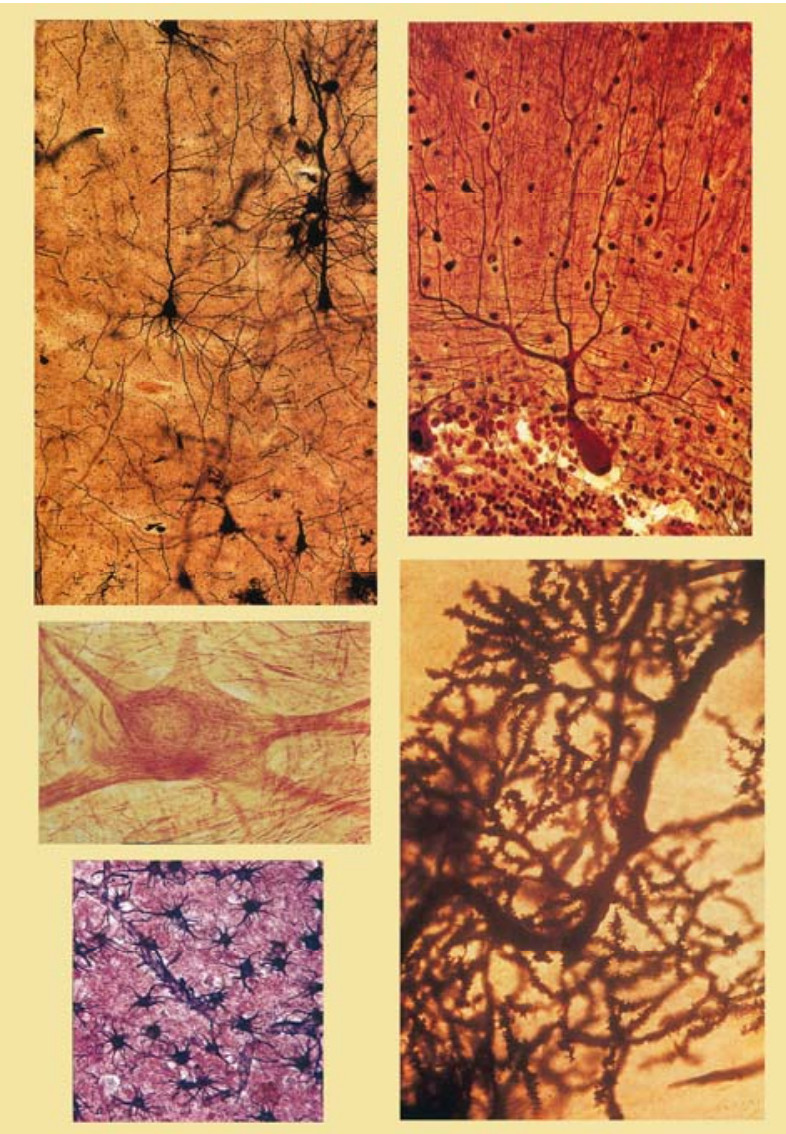

Figura 8. Conjunt de microfotografies de preparacions microscòpiques realitzades per Boya (1996) seguint les tècniques de Cajal.

\section{Cajal i Barcelona}

Encara que caldrà esperar l'estudi i publicació del conjunt de la correspondència personal de Cajal -propietat actualment dels seus hereus-, de moment, i segons els documents disponibles, sembla comunament acceptada la versió que Ramón y Cajal va abandonar la seva plaça de Barcelona animat pel desig personal d'ocupar la plaça homòloga de la Facultat de Medicina de la Universitat de Madrid. (Recerques personals, que algun dia caldrà exposar acuradament, ens aconsellen, però, no compartir aquesta versió).

La seva participació com a expositor de preparacions microgràfiques en l'Exposició Universal de Barcelona de 1888, acabat d'incorporar a la seva plaça de la Facultat de Medicina de la ciutat, fou premiat amb medalla d'or i diploma.

Abans del 20 de març de 1892, data de la seva marxa definitiva a Madrid, Cajal havia estat nomenat membre de l'Academia y Laboratorio de Ciencias Médicas de Cataluña. Pocs dies abans, el dissabte 12 de març, companys d'aquesta Acadèmia $i$ de la Facultat ofereixen al Dr. Ramón y Cajal un àpat de comiat a l'Hotel Colón de Barcelona. Entre les dues dates i a la seu d'aquella entitat hi hagueren tres conferències, les seves versions en francès i alemany abans esmentades, serien definitives per al reconeixement de Cajal en el món científic internacional.

El febrer de 1914 fou nomenat socio correspondiente de la Real Academia de Ciencias y Artes de Barcelona.

El 7 de juliol de 1919, en sessió ordinària, Cajal fou proposat soci d'honor de l'Associació de Metges i Biòlegs de Llengua Catalana.

Ni durant la seva estada a la ciutat ni quan fou premiat amb el Nobel (1906), ni quan li va arribar I'hora de la jubilació, Santiago Ramón y Cajal no va ser proposat com a membre o soci de la Reial Acadèmia de Medicina de Barcelona.

La ciutat dedicà a Ramón y Cajal un carrer en el barri de Gràcia. Cajal, en les seves memòries, situa el seu primer habitatge al carrer de la Riera Alta. Es tracta, en realitat, d'un edifici de planta triangular amb façanes a Riera Alta i Lluna, l'únic accés del qual és al número 1 del carrer de la Lluna. L'única placa commemorativa de la seva estada a Barcelona és al seu segon habitatge, al carrer del Notariat, 7, 2n, 2a. Allí hi morí la seva filla Enriqueta el 22 de juny del 1889 i hi va néixer la seva filla Pilar el 25 de juliol següent. El 14 de desembre de 1891 li va néixer, al seu probable tercer domicili al carrer Consell de Cent, el setè i darrer fill, Luis.

Per a l'estudi de l'obra de Cajal, molt dispersa i de contingut de transcendència irregular, resulta molt valuosa la relació unificada del Catàleg Collectiu de les Universitats de Catalunya (www.cbuc.cat), així com la corresponent als diferents centres del CSIC.

Es troba a faltar el vincle amb els centres documentals i biblioteques no universitàries (Arxiu Municipal de Barcelona, Biblioteca de Catalunya, Biblioteques Municipals, Museu d'Història de la Medicina de Catalunya, Biblioteca de la Reial Acadèmia de Medicina de Catalunya), que contenen una gran riquesa de fons sobre el tema. 
Entre els centres privats, la Fundació Uriach 1838 conté obra molt important i significativa de l'autor i l'Acadèmia de Ciències Mèdiques i de la Salut de Catalunya i Balears conserva la collecció de la seva anterior "Revista...", abans esmentada.

Per acabar, està per confeccionar, i no seria difícil, l'inventari globalitzat a Catalunya de qui va ser conegut en el seu temps com "le professeur de Barcelone"...

\section{Bibliografia}

Baratas, A. (2006). Ramón y Cajal. Nivola. Tres Cantos.

Boya, J. (1996). Atlas de histología y organografía microscópica. Madrid: Editorial Médica.
Calvo, A. (2001). Cajal. Triunfar a toda costa. Madrid: Alianza.

Felipe, J. de (2007). Paisajes neuronales. Homenaje a Santiago Ramón y Cajal. Madrid: CSIC.

Ferrer, D. (1989). Cajal y Barcelona. Barcelona: Fundación Uriach 1838.

López Piñero, J.M. (2000). Cajal. Barcelona: Debate.

López Piñero, J.M. (2006). Santiago Ramón y Cajal. València: Publicacions de la Universitat de València.

Ramón y Cajal, S. (1995). Historia de mi labor científica. Madrid: Alianza.

Rocha, E. (2007). La aventura científica de Santiago Ramón y Cajal. Huesca: Instituto de Estudios Altoaragoneses. 